\title{
Influence of Additions and Stratification on the Magnetic Properties and Out-of-Plane Texture of Nd-Fe-B Films
}

\author{
M. Grigoras*, N. Lupu, H. Chiriac, F. Borza, M. Urse \\ National Institute of Research \& Development for Technical Physics, 47 Mangeron Blvd., 700050 Iasi, Romania \\ Nd-Fe-B films with Ta and Mo additions used as buffer and capping layers and as interlayers have been \\ deposited by r.f. sputtering on heated $\mathrm{Si}(111)$ substrates at $370{ }^{\circ} \mathrm{C}$ and $470{ }^{\circ} \mathrm{C}$, and subsequently annealed at \\ temperatures between $550^{\circ} \mathrm{C}$ and $650^{\circ} \mathrm{C}$. In comparison with the Ta/NdFeB/Ta film, the Mo/NdFeB $/ \mathrm{Mo}$ film \\ deposited at $470^{\circ} \mathrm{C}$ presents an obvious anisotropic character. Very good anisotropic magnetic properties were \\ obtained for $\mathrm{Mo} /[\mathrm{NdFeB}(180) / \mathrm{Mo}(5)] \times 3 / \mathrm{Mo}$ multilayer film deposited at $470{ }^{\circ} \mathrm{C}$ and then annealed at $550{ }^{\circ} \mathrm{C}$. \\ This sample exhibits an increase in coercivity from $1225 \mathrm{kA} / \mathrm{m}$ up to $1651.8 \mathrm{kA} / \mathrm{m}$, increase in $M_{r} / M_{s}$ ratio \\ from 0.90 up to 0.99 , and increase in the maximum energy product from 60.4 to $121.6 \mathrm{~kJ} / \mathrm{m}^{3}$ as compared to the \\ as-deposited $\mathrm{Mo} / \mathrm{NdFeB} / \mathrm{Mo}$ film. The results demonstrate that after annealing at $550{ }^{\circ} \mathrm{C}$ the Mo film is more \\ effective for nucleation of $\mathrm{Nd}_{2} \mathrm{Fe}_{14} \mathrm{~B}$ hard magnetic grains with c-axis perpendicular to the film plane, especially in \\ Boltilayer zariant $_{\text {69 }}$ A hysPolA.126.220 \\ PACS: 75.30.Gw, 75.50.Cc, 75.50.Vv, 75.70.Ak, 75.70.Cn
}

\section{Introduction}

The out-of-plane-oriented Nd-Fe-B films, for which high $M_{r} / M_{s}$ ratio $\left(M_{r^{-}}\right.$-remanent magnetization, $M_{s^{-}}$ saturation magnetization), high coercivity $H_{c}$ and large maximum energy product $(B H)_{\max }$ can be obtained, have attracted increasing attention due to their potential applications in magnetic micro-electro-mechanical systems (MEMS), magnetic sensors, and ultra-high-density magnetic data storage [1]. The perpendicular texture of the Nd-Fe-B films depends on the substrate temperature, the nature of the material used as buffer/capping layers and interlayers, as well on the annealing temperature. Previous studies have shown that out-of-plane texture of Nd-Fe-B films can be induced by crystallization in two-steps, during deposition onto heated substrates at medium temperatures, followed by annealing at high temperatures [2]. In order to obtain Nd-Fe-B anisotropic films, Ta, Mo, or Ti are used as buffer and capping layers $[3,4]$. Ta film was also used as interlayer for multilayer films [3]. A reduced crystallization temperature for the $\mathrm{Nd}_{2} \mathrm{Fe}_{14} \mathrm{~B}$ grains is an important target. In this paper results on the influence of Ta and Mo films used as buffer, capping layers, and interlayers on the hard magnetic properties and out-of-plane texture of Nd-Fe-B films are presented. A comparison between Mo and Ta influence on the nucleation at reduced temperatures of the $\mathrm{Nd}_{2} \mathrm{Fe}_{14} \mathrm{~B}$ grains with out-of-plane orientation is presented.

\section{Experimental}

Three series of samples have been prepared for experiments: $\mathrm{Ta}(40) / \mathrm{NdFeB}(540) / \mathrm{Ta}(20)$ and $\mathrm{Mo}(40) / \mathrm{Nd}-$ $\mathrm{FeB}(540) / \mathrm{Mo}(20)$ single layer films, and $\mathrm{Mo}(40) /[\mathrm{NdFeB}$ $(180) / \mathrm{Mo}(t)] \mathrm{x} 3 / \mathrm{Mo}(20)$ multilayer films (the thickness

*corresponding author; e-mail: mgrigoras@phys-iasi.ro of each layer is in $\mathrm{nm})$. The samples have been deposited using r.f. sputtering technique on $\mathrm{Si}(111)$ substrates, heated to temperatures $T_{s}$ of $370^{\circ} \mathrm{C}$ and $470^{\circ} \mathrm{C}$. The as-deposited samples have been thermally treated for 20 minutes at temperatures ranging between $550{ }^{\circ} \mathrm{C}$ and $6500^{\circ} \mathrm{C}$.

The crystallographic structure was investigated using $\mathrm{X}$-ray diffraction (XRD) analysis.

The anisotropic hard magnetic characteristics were measured perpendicular to the film plane using a vibrating sample magnetometer (VSM) and a Physical Property Measurement System (PPMS) with a maximum magnetic field of $2460 \mathrm{kA} / \mathrm{m}$ and $3500 \mathrm{kA} / \mathrm{m}$, respectively. The demagnetization factor is not taken into consideration in the magnetic measurements.

\section{Results and discussion}

The hard magnetic properties and crystallographic structure of anisotropic Nd-Fe-B films are very sensitive to composition and substrate temperature. Figure 1 shows the hysteresis loops for Nd-Fe-B thin films with Ta and Mo films as buffer and capping layers, deposited on substrates heated to $370^{\circ} \mathrm{C}$ and $4500^{\circ} \mathrm{C}$. For $\mathrm{Ta} / \mathrm{NdFeB} / \mathrm{Ta}$ thin film deposited at $370^{\circ} \mathrm{C}$ the hysteresis loops in the as-deposited and annealed states indicate an isotropic behavior. The $470^{\circ} \mathrm{C}$ substrate temperature is favourable for the formation of the out-of-plane texture in as-deposited state, especially for $\mathrm{Mo} / \mathrm{NdFeB} / \mathrm{Mo}$ film. However, this out-of-plane texture is weak. After annealing at temperatures $\geq 550^{\circ} \mathrm{C}$ the anisotropic magnetic characteristics of $\mathrm{Ta} / \mathrm{NdFeB} / \mathrm{Ta}$ film deposited at $470{ }^{\circ} \mathrm{C}$ are slightly improved, while a decrease in the anisotropic magnetic characteristics of $\mathrm{Mo} / \mathrm{NdFeB} / \mathrm{Mo}$ thin films was observed.

In order to enhance the out-of-plane orientation of $\mathrm{Nd}_{2} \mathrm{Fe}_{14} \mathrm{~B}$ grains, the Nd-Fe-B magnetic layer was stratified in three $\mathrm{NdFeB}(180) / \mathrm{Mo}(\mathrm{t})$ bilayers. 


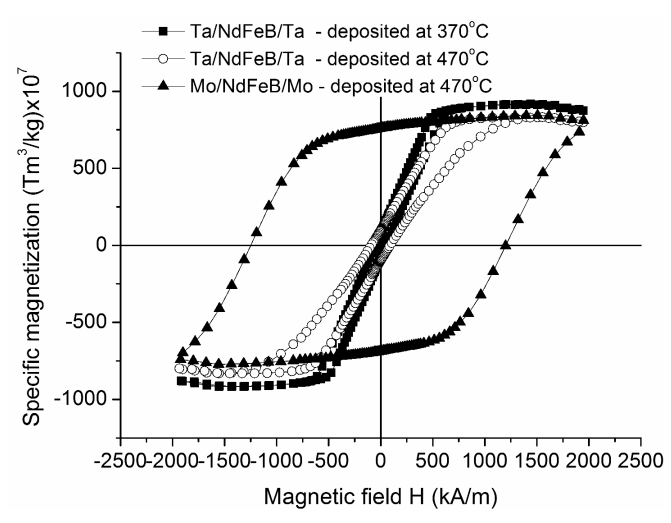

Fig. 1. Hysteresis loops of Nd-Fe-B with Ta and Mo as buffer and capping layers, deposited at $370{ }^{\circ} \mathrm{C}$ and $470^{\circ} \mathrm{C}$.

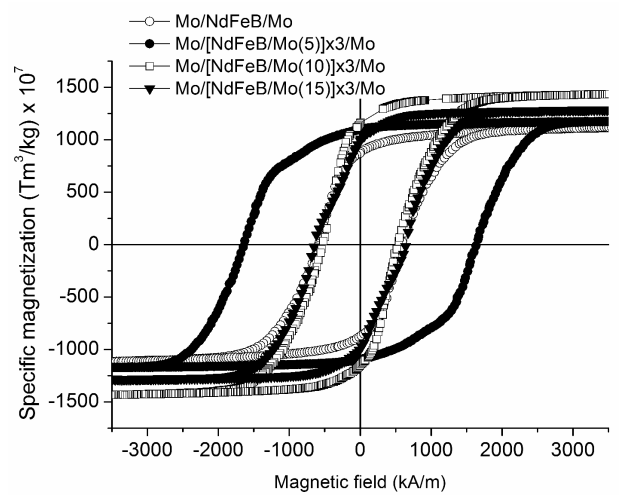

Fig. 2. Hysteresis loops of $\mathrm{Mo} / \mathrm{NdFeB} / \mathrm{Mo}$ and $\mathrm{Mo} /[\mathrm{NdFeB}(180) / \mathrm{Mo}(t)] \times 3 / \mathrm{Mo}$ films, deposited at $470{ }^{\circ} \mathrm{C}$ and annealed at $550{ }^{\circ} \mathrm{C}$.

Very good anisotropic magnetic properties were obtained for $\mathrm{Mo} /[\mathrm{NdFeB}(180) / \mathrm{Mo}(5)] \times 3 / \mathrm{Mo}$ multilayer film annealed at $550{ }^{\circ} \mathrm{C}$, i.e. the $H_{c}$ increases from $1225 \mathrm{kA} / \mathrm{m}$ up to $1651.8 \mathrm{kA} / \mathrm{m}$, the $M_{r} / M_{s}$ ratio from 0.90 up to 0.99 , and the $(B H)_{\max }$. from 60.4 up to $121.8 \mathrm{~kJ} / \mathrm{m}^{3}$, in comparison with as-deposited $\mathrm{Mo} / \mathrm{NdFeB} / \mathrm{Mo}$ film (Fig. 2). This increase is due to the enhancement of the perpendicular anisotropy.

The Ta/NdFeB/Ta films deposited at $370^{\circ} \mathrm{C}$ are amorphous. Figure 3 (a, b, c, and d) shows the XRD patterns of $\mathrm{Ta} / \mathrm{NdFeB} / \mathrm{Ta}(\mathrm{a})$, and $\mathrm{Mo} / \mathrm{NdFeB} / \mathrm{Mo}$ (b) films deposited at $470^{\circ} \mathrm{C}$, and $\mathrm{Mo} /[\mathrm{NdFeB}(180) / \mathrm{Mo}(5)] \times 3 / \mathrm{Mo}$ multilayer film deposited at $470{ }^{\circ} \mathrm{C}$ (c) and annealed at $550^{\circ} \mathrm{C}$ (d). Ta and Mo films grow during deposition having (110) orientation. The XRD patterns for asdeposited samples reveal the formation of out-of-plane oriented $\mathrm{Nd}_{2} \mathrm{Fe}_{14} \mathrm{~B}$ phases evidenced by (004), (006), (008), (105), and (214) peaks. For samples with Mo addition these phases coexist with a residual amorphous phase which vanishes after annealing at $550^{\circ} \mathrm{C}$, while the degree of orientation of the c-axis improves, especially for $\mathrm{Mo} /[\mathrm{NdFeB}(180) / \mathrm{Mo}(5)] \times 3 /$ Mo film. After annealing at temperatures $\geq 550^{\circ} \mathrm{C}$, some XRD peaks specific for Mo oxides also were evidentiated, and this is a possible reason for the decrease of the anisotropic characteristics. The oxidation effect is reduced for the multilayer sample due to protection of Mo interlayers.

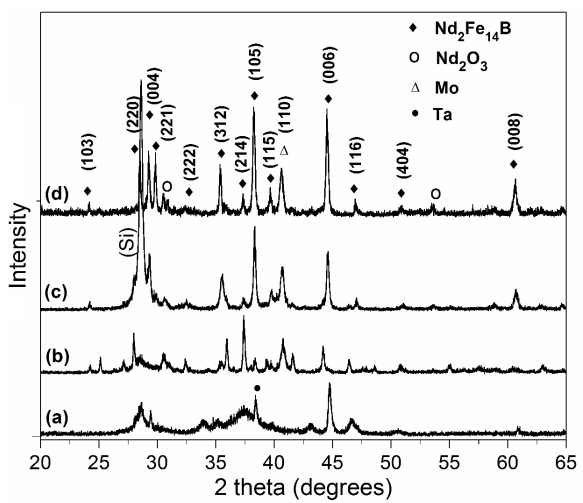

Fig. 3. XRD patterns of $\mathrm{Ta} / \mathrm{NdFeB} / \mathrm{Ta}$ (a), and $\mathrm{Mo} / \mathrm{NdFeB} / \mathrm{Mo}$ (b) films deposited at $470{ }^{\circ} \mathrm{C}$, and $\mathrm{Mo} /[\mathrm{NdFeB}(180) / \mathrm{Mo}(5)] \times 3 / \mathrm{Mo}$ film deposited at $470{ }^{\circ} \mathrm{C}(\mathrm{c})$ and annealed at $550{ }^{\circ} \mathrm{C}(\mathrm{d})$.

In order to further reduce the oxidation effect, in our future investigations, Ta films will be used as buffer and capping layers for $\mathrm{Mo} / \mathrm{NdFeB} / \mathrm{Mo}$ film both in single layer and multilayer variants. Thus, these systems will benefit of the advantages offered by the presence of Mo and Ta.

\section{Conclusions}

Investigations on the influence of Mo and Ta additions and stratification of magnetic layers on the magnetic properties and out-of-plane texture of Nd-Fe-B films have demonstrated that, in comparison to Ta film, the Mo film is more effective for the nucleation at reduced temperatures $\left(550^{\circ} \mathrm{C}\right.$ instead of $\left.650^{\circ} \mathrm{C}\right)$ of $\mathrm{Nd}_{2} \mathrm{Fe}_{14} \mathrm{~B}$ grains with c-axis perpendicular to the film plane. This tendency is stimulated by the multilayered configuration. Thus, very good anisotropic hard magnetic properties were obtained for $\mathrm{Mo} /[\mathrm{NdFeB}(180) / \mathrm{Mo}(5)] \times 3 /$ Mo multilayer films annealed at $550^{\circ} \mathrm{C}$ in comparison with $\mathrm{Mo} / \mathrm{NdFeB} / \mathrm{Mo}$ films.

\section{Acknowledgments}

This work was supported by The Ministry of National Education, Romania, project PN 0201 (Contract no. PN 09 43) - NUCLEU Program.

\section{References}

[1] V. Neu, S. Melcher, U. Hannemann, S. Fähler, L. Schultz, Phys. Rev. B 70, 144418 (2004).

[2] N.M. Dempsey, A. Walther, F. May, D. Givord, K. Khlopkov, O. Gutfleisch, Appl. Phys. Lett. 90, 092509 (2007).

[3] M. Uehara, J. Magn. Magn. Mater. 284, 281 (2004).

[4] L.K.E.B. Serrona, A. Sugimura, N. Adachi, T. Okuda, H. Ohsato, I. Sakamoto, A. Nakanishi, M. Motokawa, D.H. Ping, K. Hono, Appl. Phys. Lett. 82 82, 1751 (2003). 